\title{
Neutron activation properties of PE-B4C-concrete assessed by measurements and simulations
}

\author{
Dávid Hajdú a,b,*, Eszter Dian ${ }^{\mathrm{a}, \mathrm{c}, \mathrm{d}}$, Esben Klinkby ${ }^{\mathrm{c}, \mathrm{e}}$, Carsten P. Cooper-Jensen ${ }^{\mathrm{c}}$, János Osán ${ }^{\mathrm{a}, \mathrm{f}}$ and \\ Péter Zagyvai ${ }^{\text {a,d }}$ \\ ${ }^{a}$ Centre for Energy Research, Hungarian Academy of Sciences, Hungary \\ ${ }^{\mathrm{b}}$ Institute of Radiochemistry and Radioecology, University of Pannonia, Hungary \\ ${ }^{\mathrm{c}}$ European Spallation Source ESS ERIC, Sweden \\ ${ }^{\mathrm{d}}$ Institute of Nuclear Techniques, Budapest University of Technology and Economics, Hungary \\ e DTU Nutech, Technical University of Denmark, Denmark \\ ${ }^{\mathrm{f}}$ Nuclear Science and Instrumentation Laboratory, International Atomic Energy Agency, Austria
}

\begin{abstract}
The neutron activation properties of the PE-B4C-concrete recently developed for the European Spallation Source (ESS) ERIC (European Spallation Source, https://europeanspallationsource.se/about) were investigated. On the one hand the concrete activation was compared to that of the ordinary concrete from which it was developed by means of irradiating concrete samples in the Budapest Research Reactor (BRR) (Budapest Neutron Centre, https://www.bnc.hu/). On the other hand, the measured activities were used to study the impact of input composition on Monte Carlo activation simulations. For this purpose, the complete course of the irradiation experiments were reproduced with MCNPX and Cinder90 simulations with nominal and measured elemental concrete compositions. Simulations suggest that for realistic activation predictions more detailed elemental compositions are required than the nominal ones. Energy-dispersive X-ray fluorescence (EDXRF) analysis technique was applied for this purpose, providing fair results for short-term activation estimations.
\end{abstract}

Keywords: PE-B4C-concrete, neutron activation, Cinder90, MCNP, activation simulation

\section{Introduction}

The European Spallation Source (ESS) ERIC [5] will be the brightest one amongst the neutron sources, opening new possibilities in neutron science [13]. It also means that special attention must be paid to radiation protection planning to mitigate dose consequences of neutrons to the environment and to operating personnel. As a part of that work, a new neutron shielding material: the PE-B4C-concrete [9] was developed in the ESS. This concrete was developed from an ordinary concrete - in the following referred to as 'Reference concrete' - by replacing a certain part of the pebble-content with $\mathrm{B}_{4} \mathrm{C}$ grains and polyethylene beads, giving in total $\sim 10 \mathrm{w} \%$ of the new mixture $(0.76 \%$ and $10.2 \%$, respectively). The hydrogen content of the added polyethylene (PE) thermalizes the neutrons, while the ${ }^{10} \mathrm{~B}$ content of $\mathrm{B}_{4} \mathrm{C}$ absorbs them, providing advantageous shielding properties to the concrete. Enhanced shielding features of the PE-B4C-concrete were already investigated [8]. Our aim though was to measure the neutron activation properties of the PE-B4C-concrete, and compare them to the 'Reference concrete', as lower average activities are expected because of the added less activating components. Due to the high self-absorption of the material for alpha and beta particles, only the decay gamma radiation was examined, as main source of personnel exposure.

\footnotetext{
*Corresponding author. E-mail: hajdu.david@energia.mta.hu.
} 
Another aim was to reveal if the nominal composition (provided by the manufacturer) contains enough elements for realistic activation-related safety simulations, or more detailed composition is needed for such purposes. As the main interest of our study is the personnel safety, the focus was set on typical maintenance cases of the facility, primarily considering short-lived radioisotopes, unlike the typically performed nuclear waste production studies that are more focused on long-lived isotopes. It was also tested if simulations based on measured composition with energy-dispersive X-ray fluorescence (EDXRF) technique [15] - as a relatively cheap and easy-to-use analytical technique - can reproduce the measured activity concentration, or different analytical methods are required for this purpose.

\section{Methodology}

\subsection{Neutron activation measurements}

First, neutron activation experiments were carried out in the Budapest Research Reactor BRR [4]. The PE-B4Cconcrete and the Reference concrete samples were prepared in the following way: approximately $1 \mathrm{~g}$ portions of ground samples were measured to quartz ampoules that were placed to aluminium sample holders. The prepared samples were irradiated for 2 hours in a well-thermalized vertical irradiation channel, located in the beryllium reflector around the reactor core. Decay gamma spectra of the samples were measured in the BNC NAA Laboratory [17] with a Canberra HPGe detector 5 times after 4 to 16 days of cooling for identifying both short- and long-lived radioisotopes. In total, 30 isotopes were identified in both concretes from 12 hours $\left({ }^{42} \mathrm{~K}\right)$ to 13.5 years of half-life $\left({ }^{152} \mathrm{Eu}\right)$ as presented in Tables A1, A2. The individual and total activity concentrations were calculated and compared for both concrete types (see Fig. 1).

\subsection{EDXRF measurements}

EDXRF elemental analysis measurements were carried out in the Nuclear Science and Instrumentation Laboratory of the IAEA [10] for both the PE-B4C-concrete and the Reference concrete. After increasing the homogeneity of the samples using tungsten carbide (WC) balls and mortar, $0.25 \mathrm{~g}$ wax was added to them and pressed to $2.5 \mathrm{~g}$ pellets. It must be taken into account that the samples can be contaminated by the cobalt content of the balls and mortar. Three samples were prepared from both concretes and measured with an Epsilon 5 triaxial polarising XRF device [3]. Elemental concentrations can be calculated from the net characteristic intensities applying the fundamental parameter method [16]. EDXRF is sensitive enough to quantify trace elements but it is unable to detect elements lighter than $\mathrm{Na}$. Since a major part of concrete is formed by elements that are not detectable with EDXRF, some adjustments had to be applied. The composition of the so-called dark matrix was considered from the nominal composition of the samples. For the nominal composition of both concretes, please refer to Table 1 in [9]. The measured elemental composition of the PE-B4C and Reference concretes have already been published in [7], the same data are used in the followings. After a revision of these raw results, MCNP material cards (material compositions for Monte Carlo simulations) were generated from them, consisting of around 40 elements. In case of unmeasured bulk elements - like hydrogen, carbon, oxygen - values from the nominal composition were used to complete the material cards.

\subsection{Neutron activation simulations}

A simple model of the irradiation channel was constructed in MCNPX [14]. It included the sample as a $5 \times 5 \times$ $5 \mathrm{~mm}^{3}$ cube placed into an aluminium sample holder. The neutron source was a homogeneous volumetric source around the aluminium holder with the characteristic neutron spectrum of that irradiation channel. Simulations were performed with two so-called 'material cards' of both concrete samples, created from their measured and 
nominal compositions, as given in [7] and [9]. These nominal elemental compositions are similar to the material cards generally used for shielding design, for example the compilation of McConn Jr. et al. [11]. Densities of the Reference- and the PE-B4C-concrete were $2.33 \mathrm{~g} / \mathrm{cm}^{3}$ and $1.97 \mathrm{~g} / \mathrm{cm}^{3}$ respectively. For activation calculations, MCNPX output data were processed with Cinder90 [18]. Cinder90 generates plenty of activation products of all types of reactions, but in terms of occupational exposure only the gamma radiation is relevant, alpha- beta emitters and isotopes with very low activity do not have significant contribution. Therefore the total activity was determined as the sum of the activity concentrations of the 30 radioisotopes which were identified as gamma emitters in the irradiation measurements (see Tables A1, A2).

\section{Results and discussion}

The results of the activity measurements are presented in Fig. 1 and in Tables A1, A2. It is apparent that the total activity concentration was consequently lower in the PE-B4C-concrete than in the Reference concrete due to the added polyethylene and boron-carbide, in accordance with the expectations. In the first week of the measurement series PE-B4C-concrete had $\sim 50 \%$ lower activity concentration than the Reference concrete, meaning a significant decrease in case of a maintenance case. The difference decreased to $\sim 5 \%$ by the end of the measurement period.

The comparison of measured total activity concentration and the simulated ones with nominal composition and with EDXRF-based composition is presented in Fig. 2 for Reference concrete and in Fig. 3 for PE-B4C-concrete. EDXRF-based curves show better agreement with the measured data than nominal ones; the latter provided only $8-27 \%$ of the measured activity concentrations. Thus it is confirmed that the simulations performed with the typically used trace element free input compositions are not only not conservative, but occasionally underestimate the produced activity with one order-of-magnitude. In case of PE-B4C-concrete, EDXRF-based simulations overestimated the measured values with $30-40 \%$ - except for the first measured activity - providing conservative estimation. EDXRF-based results of Reference concrete were around the measured values within $30 \%$, except for the first point. Examining the components of the total activity concentrations it can be observed that 75$85 \%$ originated from the $15 \mathrm{~h}$ half-life ${ }^{24} \mathrm{Na}$ in the first measurement point. EDXRF technique measured around 2-times higher sodium contents than the nominal composition contained, resulting better agreements with the measured results. After 2 weeks of cooling isotopes with the order of ten days of half-life: ${ }^{86} \mathrm{Rb},{ }^{51} \mathrm{Cr},{ }^{59} \mathrm{Fe}$ and ${ }^{46} \mathrm{Sc}$ were the main sources of activity. All of their parent elements (sodium, rubidium, chromium, iron, scandium) are common components in concretes. On the basis of the related literature $[1,6,12]$ and the previous results of one of the present authors [2], iron, chromium and sodium are minor metal components of the cement, while scan-

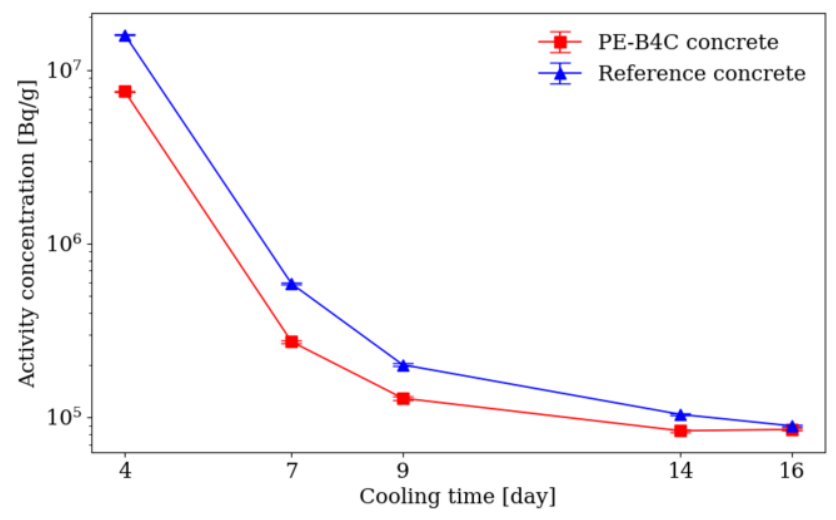

Fig. 1. Measured total activity concentrations of PE-B4C- and Reference concrete after irradiation in the BRR [4]. 


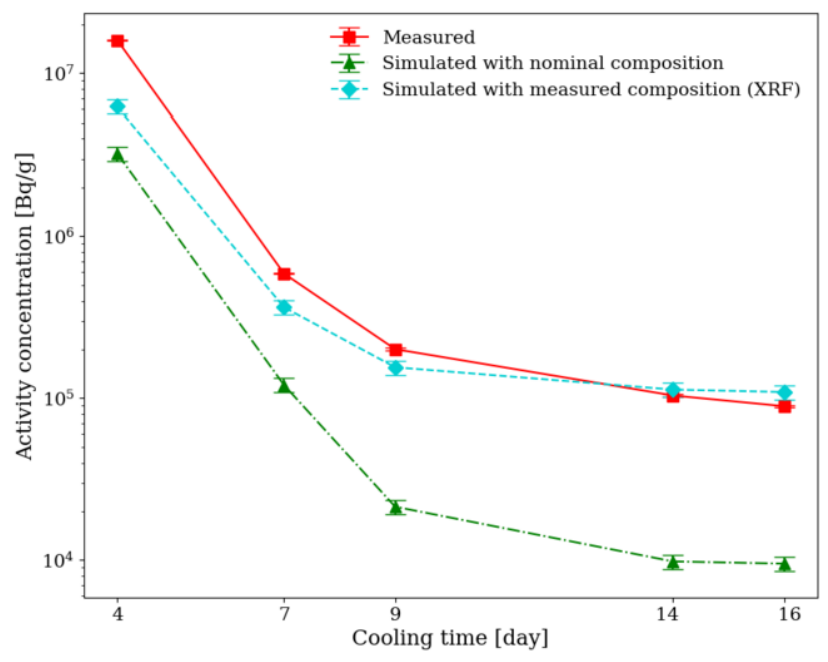

Fig. 2. Measured and simulated activity concentrations of Reference concrete.

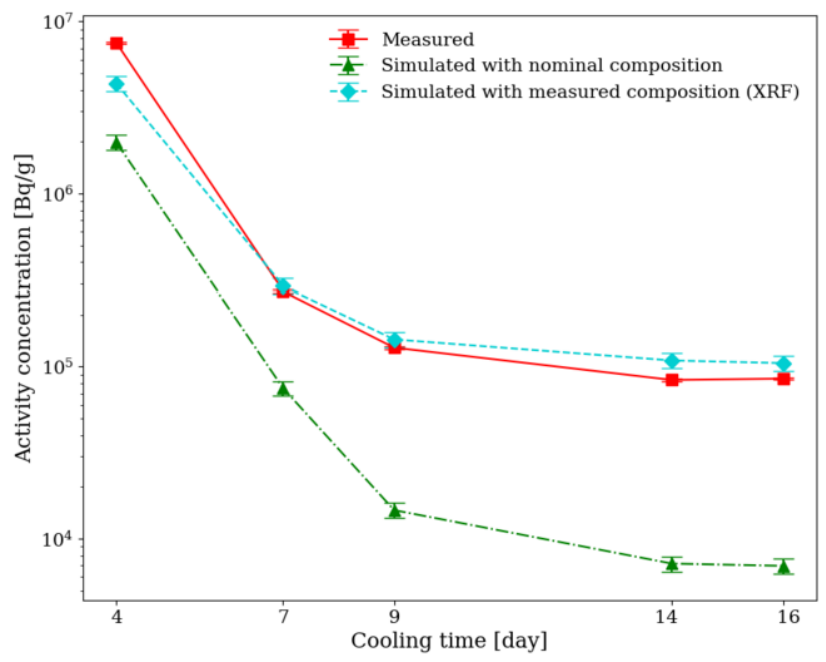

Fig. 3. Measured and simulated activity concentrations of PE-B4C-concrete.

dium and rubidium more probably originate from the gravel/pebble content of the concretes. It is important to highlight that all these elements were measured by EDXRF, while only iron content was stated in the nominal composition. It must also be noted that the differences between simulation and measurement can be caused by the inhomogeneities of the samples, so extensive sampling is essential for such highly inhomogeneous materials as concretes.

Though this study is restricted to the maintenance case and achieved promising results on the EDXRF-based simulations of short-lived activation products, it must be noted that the parent elements of the two measured neutron activation products with the longest half-lives: ${ }^{60} \mathrm{Co}(5.3 \mathrm{y})$ from cobalt and ${ }^{152} \mathrm{Eu}(13.5 \mathrm{y})$ from europium were not identified by EDXRF. Europium was below detection limit $(1 \mathrm{ppm})$, while cobalt was not measurable because of the spectral overlapping with the much higher, $(\sim 1.5 \%)$ iron content of the samples. For this reason, a complementary analytical method is required for the investigation of concretes from radioactive waste management 
point of view. For example, different XRF techniques with higher spectral resolution might solve the measurement of cobalt. Neutron activation analysis (NAA) could also be a possible solution due to its low detection limits for cobalt and europium.

\section{Conclusions}

Neutron induced activity of PE-B4C-concrete and its Reference concrete was measured and compared after irradiation in the BRR, showing 5-50\% lower activities in case of PE-B4C-concrete. The measured results were reproduced with MCNPX-Cinder90 simulations, using the nominal- and EDXRF measurement-based input compositions. Simulations with the nominal compositions, neglecting trace elements severely underestimated the measured activities, with up to one order-of-magnitude, giving a maximum of $27 \%$ of the measured total activities. On the contrary, simulations with EDXRF measurement-based material cards reproduced the measured data within mostly $30 \%$ of difference. This demonstrates that the generally used material cards does not contain enough elements for reliable activation calculations.

The discrepancies between the measured and measurement-based simulated results may come from e.g. the initial inhomogeneity of the samples. For this reason in the future we plan to refine our method e.g. extending it with the analyses of the samples with additional analytical techniques able to quantify further elements, including cobalt and europium. Moreover in order to improve the efficiency of Cinder90 data process a list of the most important radioisotopes should be defined. Material cards could also be optimized by excluding the non-activating trace elements.

\section{Acknowledgements}

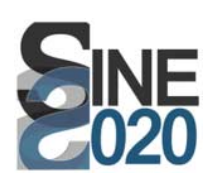

This work was performed within the World class Science and Innovation with Neutrons in Europe 2020 ("SINE2020") project, funded by the European Commission, Grant Agreement no. 654000. Computing resources provided by DMSC Computing Centre (https://europeanspallationsource.se/data-management-software/ computing-centre). 


\section{Appendix}

Table A1

Measured activity concentrations in PE-B4C-concrete

\begin{tabular}{|c|c|c|c|c|c|c|c|c|c|c|c|}
\hline \multicolumn{2}{|c|}{ Cooling time [days] } & \multicolumn{2}{|l|}{4} & \multicolumn{2}{|l|}{7} & \multicolumn{2}{|l|}{9} & \multicolumn{2}{|l|}{14} & \multicolumn{2}{|l|}{16} \\
\hline Isotope & $\mathrm{T}_{1 / 2}$ & $\begin{array}{c}\text { Activity } \\
\text { concentration }\end{array}$ & Uncertainty & $\begin{array}{c}\text { Activity } \\
\text { concentration }\end{array}$ & Uncertainty & $\begin{array}{c}\text { Activity } \\
\text { concentration }\end{array}$ & Uncertainty & $\begin{array}{c}\text { Activity } \\
\text { concentration }\end{array}$ & Uncertainty & $\begin{array}{c}\text { Activity } \\
\text { concentration }\end{array}$ & Uncertainty \\
\hline & {$[\mathrm{h}]$} & {$[\mathrm{Bq} / \mathrm{g}]$} & [\%] & {$[\mathrm{Bq} / \mathrm{g}]$} & {$[\%]$} & {$[\mathrm{Bq} / \mathrm{g}]$} & {$[\%]$} & {$[\mathrm{Bq} / \mathrm{g}]$} & {$[\%]$} & {$[\mathrm{Bq} / \mathrm{g}]$} & {$[\%]$} \\
\hline $\mathrm{K}-42$ & 12.36 & $3.80 \mathrm{E}+05$ & 15 & - & - & - & - & - & - & - & - \\
\hline $\mathrm{Na}-24$ & 14.96 & $6.45 \mathrm{E}+06$ & 1 & $1.05 \mathrm{E}+05$ & 1 & $1.07 \mathrm{E}+04$ & 2 & - & - & - & - \\
\hline W-187 & 23.72 & $4.32 \mathrm{E}+05$ & 3 & $3.25 \mathrm{E}+04$ & 3 & $7.53 \mathrm{E}+03$ & 4 & $3.62 \mathrm{E}+02$ & 26 & - & - \\
\hline As-76 & 25.87 & - & - & $2.30 \mathrm{E}+03$ & 17 & - & - & - & - & - & - \\
\hline La-140 & 40.27 & $1.15 \mathrm{E}+05$ & 4 & $1.95 \mathrm{E}+04$ & 2 & $8.43 \mathrm{E}+03$ & 1 & $1.30 \mathrm{E}+03$ & 3 & $6.89 \mathrm{E}+02$ & 4 \\
\hline Sm-153 & 46.28 & $1.29 \mathrm{E}+05$ & 8 & $3.12 \mathrm{E}+04$ & 5 & $1.52 \mathrm{E}+04$ & 4 & $2.75 \mathrm{E}+03$ & 6 & $1.66 \mathrm{E}+03$ & 6 \\
\hline Np-239 & 56.56 & - & - & $3.34 \mathrm{E}+03$ & 20 & $1.49 \mathrm{E}+03$ & 15 & $4.13 \mathrm{E}+02$ & 15 & $2.20 \mathrm{E}+02$ & 26 \\
\hline Sb-122 & 65.37 & - & - & $2.68 \mathrm{E}+03$ & 14 & $1.69 \mathrm{E}+03$ & 7 & $5.34 \mathrm{E}+02$ & 17 & $3.76 \mathrm{E}+02$ & 19 \\
\hline Sc-47 & 80.38 & - & - & $3.38 \mathrm{E}+03$ & 7 & $3.03 \mathrm{E}+03$ & 3 & $1.85 \mathrm{E}+03$ & 4 & $1.76 \mathrm{E}+03$ & 3 \\
\hline Yb-175 & 100.44 & - & - & $1.37 \mathrm{E}+04$ & 25 & $8.15 \mathrm{E}+03$ & 21 & $3.11 \mathrm{E}+03$ & 25 & $3.25 \mathrm{E}+03$ & 14 \\
\hline $\mathrm{Ca}-47$ & 108.86 & - & - & $2.08 \mathrm{E}+03$ & 17 & $1.61 \mathrm{E}+03$ & 11 & $9.49 \mathrm{E}+02$ & 5 & $7.62 \mathrm{E}+02$ & 12 \\
\hline Lu-177 & 161.62 & - & - & $5.23 \mathrm{E}+03$ & 22 & $3.11 \mathrm{E}+03$ & 15 & $1.93 \mathrm{E}+03$ & 15 & $1.79 \mathrm{E}+03$ & 12 \\
\hline Ba-131 & 276.00 & - & - & $9.86 \mathrm{E}+02$ & 10 & $1.57 \mathrm{E}+03$ & 4 & $1.40 \mathrm{E}+03$ & 4 & $1.22 \mathrm{E}+03$ & 4 \\
\hline $\mathrm{Rb}-86$ & 447.14 & - & - & - & - & $1.01 \mathrm{E}+04$ & 18 & $6.91 \mathrm{E}+03$ & 20 & $7.69 \mathrm{E}+03$ & 10 \\
\hline $\mathrm{Pa}-233$ & 647.21 & - & - & $9.65 \mathrm{E}+02$ & 12 & $2.89 \mathrm{E}+03$ & 7 & $2.82 \mathrm{E}+03$ & 5 & $3.21 \mathrm{E}+03$ & 4 \\
\hline $\mathrm{Cr}-51$ & 664.86 & - & - & $2.18 \mathrm{E}+04$ & 10 & $2.09 \mathrm{E}+04$ & 6 & $2.16 \mathrm{E}+04$ & 3 & $2.17 \mathrm{E}+04$ & 2 \\
\hline Yb-169 & 768.62 & - & - & - & - & $3.82 \mathrm{E}+02$ & 29 & $4.36 \mathrm{E}+02$ & 15 & $4.76 \mathrm{E}+02$ & 14 \\
\hline $\mathrm{Ce}-141$ & 780.02 & - & - & $1.69 \mathrm{E}+03$ & 11 & $1.73 \mathrm{E}+03$ & 8 & $1.74 \mathrm{E}+03$ & 4 & $1.99 \mathrm{E}+03$ & 3 \\
\hline Hf-181 & 1017.36 & - & - & - & - & $8.03 E+02$ & 8 & $9.02 \mathrm{E}+02$ & 4 & $1.05 \mathrm{E}+03$ & 3 \\
\hline Fe-59 & 1068.07 & - & - & $1.13 \mathrm{E}+04$ & 4 & $1.21 \mathrm{E}+04$ & 2 & $1.34 \mathrm{E}+04$ & 1 & $1.42 \mathrm{E}+04$ & 2 \\
\hline Sb-124 & 1444.80 & - & - & - & - & - & - & $2.69 \mathrm{E}+02$ & 6 & $3.43 \mathrm{E}+02$ & 6 \\
\hline Sr- 85 & 1556.16 & - & - & - & - & - & - & $1.56 \mathrm{E}+02$ & 23 & $2.12 \mathrm{E}+02$ & 26 \\
\hline Tb-160 & 1735.20 & - & - & - & - & - & - & $5.56 \mathrm{E}+02$ & 16 & $6.11 \mathrm{E}+02$ & 10 \\
\hline Sc-46 & 2010.96 & $2.22 \mathrm{E}+04$ & 23 & $1.30 \mathrm{E}+04$ & 2 & $1.26 \mathrm{E}+04$ & 2 & $1.44 \mathrm{E}+04$ & 1 & $1.58 \mathrm{E}+04$ & 1 \\
\hline Ta-182 & 2746.32 & - & - & - & - & - & - & $5.01 \mathrm{E}+02$ & 22 & $3.83 \mathrm{E}+02$ & 22 \\
\hline $\mathrm{Zn}-65$ & 5862.24 & - & - & $1.57 \mathrm{E}+03$ & 24 & $1.35 \mathrm{E}+03$ & 13 & $1.65 \mathrm{E}+03$ & 7 & $1.90 \mathrm{E}+03$ & 6 \\
\hline Mn-54 & 7495.20 & - & - & - & - & - & - & $2.96 \mathrm{E}+02$ & 25 & $2.25 \mathrm{E}+02$ & 25 \\
\hline Cs-134 & 18087.65 & - & - & - & - & $4.49 \mathrm{E}+02$ & 12 & $5.90 \mathrm{E}+02$ & 6 & $6.06 \mathrm{E}+02$ & 5 \\
\hline Co-60 & 46177.46 & - & - & $1.14 \mathrm{E}+03$ & 16 & $1.15 \mathrm{E}+03$ & 6 & $1.31 \mathrm{E}+03$ & 2 & $1.43 \mathrm{E}+03$ & 3 \\
\hline Eu-152 & 118584.12 & - & - & - & - & $1.58 \mathrm{E}+03$ & 7 & $1.46 \mathrm{E}+03$ & 4 & $1.74 \mathrm{E}+03$ & 2 \\
\hline
\end{tabular}


Table A2

Measured activity concentrations in Reference concrete

\begin{tabular}{|c|c|c|c|c|c|c|c|c|c|c|c|}
\hline \multicolumn{2}{|c|}{ Cooling time [days] } & \multicolumn{2}{|l|}{4} & \multicolumn{2}{|l|}{7} & \multicolumn{2}{|l|}{9} & \multicolumn{2}{|l|}{14} & \multicolumn{2}{|l|}{16} \\
\hline Isotope & $\mathrm{T}_{1 / 2}$ & $\begin{array}{c}\text { Activity } \\
\text { concentration }\end{array}$ & Uncertainty & $\begin{array}{c}\text { Activity } \\
\text { concentration }\end{array}$ & Uncertainty & $\begin{array}{c}\text { Activity } \\
\text { concentration }\end{array}$ & Uncertainty & $\begin{array}{c}\text { Activity } \\
\text { concentration }\end{array}$ & Uncertainty & $\begin{array}{c}\text { Activity } \\
\text { concentration }\end{array}$ & Uncertainty \\
\hline & {$[\mathrm{h}]$} & {$[\mathrm{Bq} / \mathrm{g}]$} & {$[\%]$} & {$[\mathrm{Bq} / \mathrm{g}]$} & {$[\%]$} & {$[\mathrm{Bq} / \mathrm{g}]$} & {$[\%]$} & {$[\mathrm{Bq} / \mathrm{g}]$} & {$[\%]$} & {$[\mathrm{Bq} / \mathrm{g}]$} & {$[\%]$} \\
\hline $\mathrm{K}-42$ & 12.36 & $5.23 \mathrm{E}+05$ & 11 & $4.77 \mathrm{E}+03$ & 25 & - & - & - & - & - & - \\
\hline $\mathrm{Na}-24$ & 14.96 & $1.18 \mathrm{E}+07$ & 1 & $1.82 \mathrm{E}+05$ & 1 & $1.61 \mathrm{E}+04$ & 2 & - & - & - & - \\
\hline W-187 & 23.72 & $3.77 \mathrm{E}+06$ & 1 & $2.54 \mathrm{E}+05$ & 1 & $5.53 \mathrm{E}+04$ & 1 & $1.82 \mathrm{E}+03$ & 6 & $4.60 \mathrm{E}+02$ & 21 \\
\hline As-76 & 25.87 & $0.00 \mathrm{E}+00$ & - & $1.57 \mathrm{E}+03$ & 26 & $6.23 \mathrm{E}+02$ & 21 & - & - & - & - \\
\hline La-140 & 40.27 & $2.14 \mathrm{E}+05$ & 3 & $3.32 \mathrm{E}+04$ & 1 & $1.34 \mathrm{E}+04$ & 1 & $2.08 \mathrm{E}+03$ & 3 & $9.99 \mathrm{E}+02$ & 3 \\
\hline Sm-153 & 46.28 & $2.22 \mathrm{E}+05$ & 5 & $4.93 \mathrm{E}+04$ & 4 & $2.24 \mathrm{E}+04$ & 3 & $4.34 \mathrm{E}+03$ & 4 & $2.06 \mathrm{E}+03$ & 6 \\
\hline Np-239 & 56.56 & - & - & $5.94 \mathrm{E}+03$ & 12 & $1.86 \mathrm{E}+03$ & 14 & $5.82 \mathrm{E}+02$ & 18 & $3.25 \mathrm{E}+02$ & 25 \\
\hline Sb-122 & 65.37 & - & - & $2.80 \mathrm{E}+03$ & 12 & $1.54 \mathrm{E}+03$ & 9 & $5.32 \mathrm{E}+02$ & 21 & $3.29 \mathrm{E}+02$ & 19 \\
\hline Sc-47 & 80.38 & - & - & $4.22 \mathrm{E}+03$ & 10 & $2.95 \mathrm{E}+03$ & 6 & $2.04 \mathrm{E}+03$ & 4 & $1.53 \mathrm{E}+03$ & 5 \\
\hline Yb-175 & 100.44 & - & - & - & - & $9.44 \mathrm{E}+03$ & 21 & $5.02 \mathrm{E}+03$ & 14 & $3.22 \mathrm{E}+03$ & 20 \\
\hline $\mathrm{Ca}-47$ & 108.86 & - & - & $2.04 \mathrm{E}+03$ & 13 & $1.86 \mathrm{E}+03$ & 13 & $1.08 \mathrm{E}+03$ & 10 & $6.99 \mathrm{E}+02$ & 11 \\
\hline Lu-177 & 161.62 & - & - & - & - & $3.54 \mathrm{E}+03$ & 24 & $2.72 \mathrm{E}+03$ & 11 & $2.28 \mathrm{E}+03$ & 10 \\
\hline Ba-131 & 276.00 & - & - & $2.39 \mathrm{E}+03$ & 12 & $2.26 \mathrm{E}+03$ & 5 & $1.94 \mathrm{E}+03$ & 3 & $1.62 \mathrm{E}+03$ & 3 \\
\hline $\mathrm{Rb}-86$ & 447.14 & - & - & - & - & $1.12 \mathrm{E}+04$ & 14 & $1.09 \mathrm{E}+04$ & 11 & $1.01 \mathrm{E}+04$ & 9 \\
\hline $\mathrm{Pa}-233$ & 647.21 & - & - & - & - & $6.08 \mathrm{E}+03$ & 9 & $5.96 \mathrm{E}+03$ & 4 & $5.43 \mathrm{E}+03$ & 3 \\
\hline $\mathrm{Cr}-51$ & 664.86 & - & - & $1.70 \mathrm{E}+04$ & 22 & $1.49 \mathrm{E}+04$ & 9 & $1.67 \mathrm{E}+04$ & 2 & $1.55 \mathrm{E}+04$ & 5 \\
\hline Yb-169 & 768.62 & - & - & - & - & - & - & $6.15 \mathrm{E}+02$ & 14 & $5.12 \mathrm{E}+02$ & 11 \\
\hline $\mathrm{Ce}-141$ & 780.02 & - & - & $3.08 \mathrm{E}+03$ & 12 & $3.23 \mathrm{E}+03$ & 7 & $3.02 \mathrm{E}+03$ & 4 & $2.79 \mathrm{E}+03$ & 3 \\
\hline Hf-181 & 1017.36 & - & - & $1.34 \mathrm{E}+03$ & 21 & $1.07 \mathrm{E}+03$ & 13 & $1.15 \mathrm{E}+03$ & 6 & $1.16 \mathrm{E}+03$ & 4 \\
\hline $\mathrm{Fe}-59$ & 1068.07 & - & - & $1.34 \mathrm{E}+04$ & 4 & $1.27 \mathrm{E}+04$ & 3 & $1.53 \mathrm{E}+04$ & 1 & $1.39 \mathrm{E}+04$ & 1 \\
\hline Sb-124 & 1444.80 & - & - & - & - & - & - & $3.13 \mathrm{E}+02$ & 7 & $2.49 \mathrm{E}+02$ & 14 \\
\hline Sr- 85 & 1556.16 & - & - & - & - & - & - & $2.47 \mathrm{E}+02$ & 18 & $3.16 \mathrm{E}+02$ & 19 \\
\hline Tb-160 & 1735.20 & - & - & - & - & - & - & $7.03 \mathrm{E}+02$ & 18 & $7.12 \mathrm{E}+02$ & 9 \\
\hline Sc-46 & 2010.96 & - & - & - & - & $1.59 \mathrm{E}+04$ & 2 & $1.94 \mathrm{E}+04$ & 1 & $1.82 \mathrm{E}+04$ & 1 \\
\hline Та-182 & 2746.32 & - & - & - & - & - & - & $6.97 \mathrm{E}+02$ & 14 & $5.67 \mathrm{E}+02$ & 11 \\
\hline $\mathrm{Zn}-65$ & 5862.24 & - & - & - & - & $1.36 \mathrm{E}+03$ & 25 & $1.95 \mathrm{E}+03$ & 9 & $1.79 \mathrm{E}+03$ & 13 \\
\hline $\mathrm{Mn}-54$ & 7495.20 & - & - & - & - & - & - & - & - & $2.80 \mathrm{E}+02$ & 22 \\
\hline Cs-134 & 18087.65 & - & - & - & - & $7.11 \mathrm{E}+02$ & 15 & $7.29 \mathrm{E}+02$ & 5 & $7.78 \mathrm{E}+02$ & 5 \\
\hline Co-60 & 46177.46 & - & - & $1.30 \mathrm{E}+03$ & 13 & $1.09 \mathrm{E}+03$ & 10 & $1.54 \mathrm{E}+03$ & 3 & $1.42 \mathrm{E}+03$ & 2 \\
\hline Eu-152 & 118584.12 & - & - & - & - & $1.73 \mathrm{E}+03$ & 9 & $2.33 \mathrm{E}+03$ & 4 & $2.07 \mathrm{E}+03$ & 3 \\
\hline
\end{tabular}

\section{References}

[1] Precision Measurement and Calibration, Vol. III, National Bureau of Standards Handbook, Vol. 77, 1961. https://www-s.nist.gov/srmors/ certificates/archives/791.pdf.

[2] Hungarian Academy of Sciences, Centre for Energy Research: Progress Report on Research Activities in 2017, 2017, https://www.energia. mta.hu/ aekimhp/EK/MTA_EK_Evkonyv_2017_teljes.pdf.

[3] Epsilon 5 integrated X-ray analysis system. http://www.speciation.net/Database/Instruments/PANalytical-BV/Epsilon-5-;i1663.

[4] Budapest Neutron Centre. https://www.bnc.hu/.

[5] European Spallation Source (ESS). https://europeanspallationsource.se/about.

[6] Certified Reference Material IAG CRM-3, 2009. https://www-s.nist.gov/srmors/view_detail.cfm?srm=1885b.

[7] E. Dian, E. Klinkby, C.P. Cooper-Jensen, D. Párkányi, D. Hajdu, J. Osán, G. Patriskov, U. Filges and P.M. Bentley, Preparation for activation measurements of concrete and PE-B4C-concrete to be applied for shielding at the European Spallation Source, J. Phys. Conf. Ser. 1021(1) (2018), 012050. doi:10.1088/1742-6596/1021/1/012050.

[8] D.D. DiJulio, C.P. Cooper-Jensen, I. Llamas-Jansa, S. Kazi and P.M. Bentley, Measurements and Monte-Carlo simulations of the particle self-shielding effect of B4C grains in neutron shielding concrete, Radiat. Phys. Chem. 147 (2018), 40-44. doi:10.1016/j.radphyschem. 2018.01.023. 
[9] D.D. DiJulio, C.P. Cooper-Jensen, H. Perrey, K. Fissum, E. Rofors, J. Scherzinger and P.M. Bentley, A polyethylene-B4C based concrete for enhanced neutron shielding at neutron research facilities, Nucl. Instruments Methods Phys. Res. Sect. A Accel. Spectrometers, Detect. Assoc. Equip. 859 (2017), 41-46. doi:10.1016/j.nima.2017.03.064.

[10] IAEA, Seibersdorf laboratories. https://www.iaea.org/about/organizational-structure/department-of-nuclear-sciences-and-applications/ seibersdorf-laboratories.

[11] R. McConn Jr., C. Gesh, R. Pagh, R. Rucker, R. Williams, Compendium of Material Composition Data for Radiation Transport Modeling, Pacific Northwest National Laboratory, Richland, WA, 2011. http://www.pnnl.gov/main/publications/external/technical_reports/ PNNL-15870Rev1.pdf. doi:10.2172/1023125.

[12] NIST, SRM 1885b - Portland Cement. https://www-s.nist.gov/srmors/view_detail.cfm?srm=1885b.

[13] S. Peggs, ESS Technical Design Report, 2013. ISBN 9789198017328. http://eval.esss.lu.se/cgi-bin/public/DocDB/ShowDocument? docid $=274$.

[14] D.B. Pelowitz, MCNPX ${ }^{\mathrm{TM}}$ User's Manual, 2011.

[15] P.J. Potts and C. Vanhoof, 2015 Atomic Spectrometry Update - A review of advances in X-ray fluorescence spectrometry and their applications, J. Anal. At. Spectrom. 30 (2015), 1706-1755. doi:10.1039/c5ja90033f.

[16] C.-U. Ro, J. Osán, I. Szalóki, J. de Hoog, A. Worobiec and R.V. Grieken, A Monte Carlo program for quantitative electron-induced X-ray analysis of individual particles, Anal. Chem. 75(4) (2003), 851-859. doi:10.1021/ac025973r.

[17] L. Szentmiklósi, D. Párkányi and I. Sziklai-László, Upgrade of the Budapest neutron activation analysis laboratory, J. Radioanal. Nucl. Chem. 309(1) (2016), 91-99. doi:10.1007/s10967-016-4776-7.

[18] W.B. Wilson, S.T. Cowell, T.R. England, A.C. Hayes, P. Moller, A Manual for CINDER'90 Version 07.4 Codes and Data, LA-UR-078412, Los Alamos National Laboratory, 2008. 